\title{
A gestational vulnerability window for smoking exposure and the increased risk of preterm birth: how timing and intensity of maternal smoking matter
}

\author{
Anthony J. Kondracki (D) and Sandra L. Hofferth
}

\begin{abstract}
Background: Reducing the incidence of preterm birth is a national priority. Maternal cigarette smoking is strongly and consistently associated with preterm birth. The objective of this study was to examine prenatal exposure based on combined measures of timing (by trimester) and intensity level (the number of cigarettes smoked per day) of maternal smoking to identify a pregnancy period with the highest risk of preterm birth.

Methods: A sample of 2,485,743 singleton births was drawn from the 2010 National Center of Health Statistics (NCHS) linked birth/infant death file of US residents in 33 states that implemented the revised 2003 birth certificate. Nine mutually exclusive smoking status categories were created to assess prenatal exposure across pregnancy in association with preterm birth. Gestational age was based on the obstetric estimate. Multiple logistic regression analyses were conducted to compare the odds of preterm birth among women who smoked at different intensity levels in the second or third trimester with those who smoked only in the first trimester.

Results: Overall, $7.95 \%$ of women had a preterm birth; $8.90 \%$ of low intensity (less than a pack/day) smokers in the first trimester only, $12.99 \%$ of low and $15.38 \%$ of high intensity (pack a day or more) smokers in the first two trimesters, and $10.56 \%$ of low and $11.35 \%$ of high intensity smokers in all three trimesters delivered preterm. First and second trimester high (aOR 1.85, 95\% Cl: 1.66, 2.06) and low intensity smokers (aOR 1.51,95\% Cl: 1.41, 1.61) had higher odds of preterm birth compared to those who smoked less than a pack a day only in the first trimester, but the odds did not increase for all three trimester smokers relative to the first and second trimester smokers. In sensitivity analysis, adjustment for exposure misclassification error corrected data and testing for effect modification by maternal race/ ethnicity found no significant interaction.

Conclusions: This study documented a biologically plausible vulnerability window for smoking exposure and the increased risk of preterm birth. For women who do not modify their smoking behavior preconception, preterm birth risk of smoking remains low until late in the first trimester.
\end{abstract}

Keywords: Preterm birth, Trimester, Pregnancy, Timing of smoking, Cessation

\footnotetext{
* Correspondence: akondrac@umd.edu

School of Public Health, Department of Family Science, University of Maryland, 4200 Valley Drive, College Park, MD 20742, USA
}

(c) The Author(s). 2019 Open Access This article is distributed under the terms of the Creative Commons Attribution 4.0 International License (http://creativecommons.org/licenses/by/4.0/), which permits unrestricted use, distribution, and reproduction in any medium, provided you give appropriate credit to the original author(s) and the source, provide a link to the Creative Commons license, and indicate if changes were made. The Creative Commons Public Domain Dedication waiver (http://creativecommons.org/publicdomain/zero/1.0/) applies to the data made available in this article, unless otherwise stated. 


\section{Plain English summary}

Preterm birth before 37 weeks gestation occurs in about 5 to $18 \%$ of all pregnancies and is associated with increased morbidity and mortality in newborns. Smoking during pregnancy is a potentially preventable risk factor for preterm birth, yet nearly one-third of reproductive age women (18-44 years old) are daily smokers and at least half of women continue smoking during pregnancy. Infants whose mothers do not smoke at all have dramatically better outcomes. Although women try to quit smoking upon pregnancy recognition, little is known about when smoking cessation during pregnancy matters most for preterm birth. To date, few studies thoroughly examined variability in patterns of timing and intensity of smoking to capture the extent of prenatal exposure across trimesters of pregnancy. This is the first population-based study to utilize combined measures of timing, intensity and duration of maternal smoking to identify a potential biologically plausible window of enhanced vulnerability to smoking exposure, which is late in the first trimester, to avoid preterm birth.

\section{Background}

Preterm birth of less than 37 weeks gestation occurs in about 5 to $18 \%$ of pregnancies. [1] Reducing the incidence of preterm birth by $10 \%$ is a key objective of Healthy People 2020. [2]

In the United States, the overall rate of preterm birth rose from $9.63 \%$ in 2015 to $9.85 \%$ in 2016 and to $9.93 \%$ in 2017 , and for singleton births only the rate increased from $7.82 \%$ in 2015 to $8.02 \%$ in 2016 and to $8.13 \%$ in 2017 . [3] Racial and ethnic disparities exist such that in 2017 non-Hispanic Black (13.93\%) and Hispanic mothers (9.62\%) had a higher rate of preterm birth than non-Hispanic White (9.05\%) or Asian mothers (8.53\%). [3] About 5\% of preterm births are extremely preterm (20 $0 / 7$ to $276 / 7$ weeks gestation), $15 \%$ severely preterm (28 $0 / 7$ to $316 / 7$ weeks), $20 \%$ moderately preterm (32 0/7 to $336 / 7$ weeks), and the majority (60\%) and the fastest growing group are late preterm births (34 0/7 to $366 / 7$ weeks gestation). [4] In the US in 2010, two-thirds (66.7\%) of all infant deaths were attributed to the $12 \%$ of infants born preterm. [5] The mortality rate for infants born very preterm was 165.57 per 1000 of live births, which was 74 times the rate of 2.25 for term infants, and for moderately preterm infants the rate was 15.83 , which was seven times the rate for term infants. [5] Shortened gestational age indicates newborn immaturity and predicts poor health at birth and during the life course. [6] Estimated health care costs related to preterm delivery, reported in 2005, were at least $\$ 26$ billion annually ( $\$ 51,600$ per infant). [6]

Approximately one-third of reproductive age women (18-44) in the US are daily cigarette smokers. [7] Tobacco smoke contains more than 4000 harmful chemicals among which nicotine is the most addictive substance and a reproductive toxicant. [8] Maternal smoking has been recognized as an independent risk factor for preterm birth, fetal growth restriction and low birthweight, [9-11] and has been associated with miscarriage, [12] placenta praevia and placental abruption. [13] Health care expenses for smoking mothers and their newborns can be $66 \%$ higher than for nonsmoking mothers. [14]

National reports indicate that smoking in pregnancy is more prevalent among non-Hispanic White women, 2024 years old, and less educated women. [7] Among the $10.9 \%$ of women who smoked in the 3 months prior to pregnancy, $24.2 \%$ quit smoking before becoming pregnant and $8.4 \%$ of women smoked at any time during pregnancy. [7] The prevalence of smoking was $8.2 \%$ in the first trimester, $7.0 \%$ in the second and $6.6 \%$ in the third trimester. [7] On average, one fifth of smoking pregnant women quit spontaneously at the time of their first prenatal visit, but $70 \%$ of those who quit, returned to smoking within six months after childbirth. $[15,16]$ Women 18-24 years old were most likely to have attempted to quit $(68.4 \%)$, but least likely to have quit smoking (26.3\%) in pregnancy. [15]

It is well documented that infants whose mothers do not smoke at all have dramatically better outcomes, but little is known whether and when during pregnancy smoking cessation matters for preterm birth. Prior studies linking evidence of smoking any time during pregnancy with the increased risk of adverse birth outcomes suggested that quitting early in pregnancy reduced $[9,17]$ or reversed such risk. [18] Based on an 11-state US subpopulation analysis, quitting in the first trimester lowered the risk of delivering preterm by $31 \%$, to the level of nonsmokers, whereas smoking into the second trimester and then quitting did not have the same effect. [19] Some researchers questioned whether the number of cigarettes smoked increases the risk of delivering a growth restricted and low birthweight infant $[9,10,20]$ and how it influences the risk of both overall and spontaneous preterm birth. [17] Smoking more than ten cigarettes per day has been significantly linked to preterm delivery $[17,20]$ and a greater number of cigarettes smoked, irrespective of trimester of pregnancy, is likely to increase the risk. [20]

Given low rates of quitting and high rates of relapse among women who smoke in the first trimester of pregnancy, $[15,16]$ we seek to understand the implications of prenatal exposure from continued smoking or quitting early or later in pregnancy. Associations with preterm birth were most commonly reported for maternal smoking in early pregnancy (the first trimester) [19] or mid-trimester; [21] however, a specific time by which smoking in pregnancy must stop to prevent preterm delivery is unclear. To examine prenatal exposure status more thoroughly in association with the increased risk of preterm birth, we 
combined measures of timing (per trimester), intensity (by the number of cigarettes smoked per day) and duration (consistency) of maternal smoking into nine mutually exclusive smoking status categories. We hypothesize that systematically comparing various smoking patterns across trimesters of pregnancy can establish smoking exposure and help identify biologically plausible window(s) for enhanced vulnerability to preterm birth.

\section{Methods}

\section{Data source}

As a data source in this study, we used the electronic 2010 National Center for Health Statistics (NCHS) linked birth/ infant death dataset $(N=4,007,105)$ of all births registered in the 33 states that had implemented the 2003 revised version of the birth certificate, representing $76 \%$ of all US births. [5] The NCHS in cooperation with the National Vital Statistics System (NVSS) include birth certificate data in the natality file allowing public access to deidentified information. [22] During the twentieth century, the birth certificate had 11 revisions to improve "completeness and accuracy" of data collection and reporting, [24] and the last 2003 revised version gradually replaced the previous 1989 version across the country. [23] Availability of more detailed information on the timing and intensity of smoking during pregnancy in the 2003 revised version made this study possible. [24]

\section{Study population and study design}

This cross-sectional study included the entire population of 2,485,743 singleton live births in the United States in 2010, after excluding multiple births $(n=138,264)$, births in states with unrevised certificates $(n=906,068)$, births with missing data on maternal race $(n=2146)$ and on other maternal demographic characteristics $(n=10,214)$, and on smoking by trimester $(n=465,084)$.

\section{Definition and measurement}

Pregnancy was defined by three trimesters (gestational stages): the first trimester (months 1-3- or 1-13-weeks gestation), the second trimester (months 4-6 or 14-27 weeks gestation), and the third trimester (months 7-9 or 28 weeks to delivery). [25]

Preterm birth was defined as delivering a singleton newborn between 20 and less than 37 weeks gestation, based on the best obstetric estimate (OE) of gestation at birth that combines date of maternal last menstrual period (LMP) and ultrasound (US) measurement available in the revised birth certificate. [26] The OE has more validity than the LMP-based estimate alone, because recall error is minimized and births are less likely to be misclassified. [27]

A vulnerability window for prenatal smoking exposure was defined as the most sensitive period (trimester) in pregnancy $[28,29]$, as indicated by the increased odds of preterm birth.

\section{Exposure variable}

The exposure variable was cigarette smoking during pregnancy. On the revised birth certificate the mother reports the average number of cigarettes smoked per day in each trimester of pregnancy and before pregnancy. [7] In this study, timing of cigarette smoking was measured by trimester and intensity level was classified as low intensity (1-19 cigarettes/day or less than a pack/day) and high intensity ( $\geq 20$ cigarettes/day or a pack/day or more), based on prior research. [20]

\section{Outcome variable}

The outcome variable was preterm birth defined categorically based on gestational age of less than 37 weeks gestation or between 20 0/7 and 36 6/7 weeks gestation.

\section{Covariates}

We combined race and ethnicity to form five categories: non-Hispanic White, non-Hispanic Black, Hispanic, non-Hispanic Asian, and American Indian. Maternal age categories were $12-19,20-34$ and 35 years old or older; maternal education was categorized as less than high school, high school graduate, some college or associate degree, and a bachelor's degree or higher; and marital status was married or unmarried.

\section{Exposure status}

Prenatal exposure status was examined based on variability in maternal smoking patterns across trimesters. [30-32] Women who quit smoking before pregnancy appeared to have a rate of exposure similar to non-smoking women [21] and we did not study them separately. We assumed that women who reported smoking were active smokers because nonsmokers would be less likely to report active smoking in pregnancy. [33, 34] We classified women as non-smoking only if they reported no cigarette use during any trimester. Consistent ever-smokers could have smoked in the first trimester only, in the first and second trimesters only, or in all three trimesters. A small proportion of women were inconsistent smokers who reported smoking in the first and in the third trimester only and denied smoking in the second trimester, who reported smoking in the second trimester only or in the second and the third trimester, or who smoked only in the third trimester.

Our study advanced standard methodology by creating nine mutually exclusive smoking intensity status categories combining measures of timing (trimesters in which smoking was reported), intensity (the number of cigarettes smoked per day) and duration (consistency across trimesters) of smoking to thoroughly assess distribution of prenatal exposure across trimesters: low-intensity 
smokers (1-19 cigarettes/day or less than a pack/day) in the first but not in the second trimester (reference group); high-intensity smokers ( $\geq 20$ cigarettes/day or a pack/day or more) in the first but not in the second trimester; low-intensity smokers in the first and second trimesters; high-intensity smokers in the first and second trimesters; low-intensity smokers who started smoking in the second or third trimesters (did not smoke in the first trimester); high-intensity smokers who started smoking in the second or third trimesters; low-intensity smokers in all three trimesters; high-intensity smokers in all three trimesters; and nonsmokers (no trimester smokers).

\section{Quality of self-reported smoking data}

Almost 25\% of pregnant women do not disclose smoking throughout pregnancy, related in part to social stigma [3638]. Information on smoking during pregnancy collected from mothers on birth certificates showed moderate to high agreement when compared to other self-reported information from the Pregnancy Risk Assessment Monitoring System (PRAMS), and slightly less agreement when compared with medical records. [36, 37] Third trimester prenatal smoking reported on the birth certificate was highly correlated with newborn cotinine levels. [35] Cotinine is a primary product of nicotine metabolism detected in blood, saliva or urine, and is considered a biochemical marker (biomarker) and gold standard measure of choice to validate current smoking status. [39, 40] While prior prospective epidemiological studies showed cotinine levels to be correlated with self-reported number of cigarettes smoked at any given time in pregnancy, the results have been inconclusive among self-reported quitters. [27, 31, 41, 42]

\section{Statistical analyses}

In this study, the entire population of $2,485,743$ singleton live births in the US in 2010 was separated into two gestational age subgroups: births between 20 weeks gestation and term (second and third trimester births) and births between 28 weeks gestation and term (third trimester births only). Conceptually, we first estimated preterm birth $(20-<37$ weeks gestation) rates for these two gestational age subgroups across maternal race/ethnicity, age, educational attainment and marital status (Table 1), and performed similar analyses according to maternal smoking status categories (Table 2). Next, we conducted multiple logistic regression analyses to assess crude (without adjustment for confounding) and adjusted (with adjustment for confounding) odds ratios of preterm births and 95\% confidence intervals (Table 3). To identify a potential vulnerability window during which prenatal smoking exposure exerts greatest effect on the increased risk of preterm birth, we sought a combination of trimester-timing and intensity-level maternal smoking

Table 1 Percentage of all preterm births (20- $<37$ weeks gestation) and third trimester preterm births $(28-<37$ weeks gestation) across maternal characteristics, singleton births, United States, 2010

\begin{tabular}{llll}
\hline & $\mathrm{N}(\%)$ & Preterm (\%) $20-<37$ weeks & Preterm (\%) $28-<37$ weeks \\
\hline Total N (\%) & $2,485,743(100)$ & $(7.95)$ & $(7.49)$ \\
Race/ethnicity & & $(7.27)$ & $(6.94)$ \\
Non-Hispanic White & $1,320,489(53.12)$ & $(11.48)$ & $(10.37)$ \\
Non-Hispanic Black & $296,389(11.92)$ & $(7.84)$ & $(6.96)$ \\
Hispanic & $690,911(27.79)$ & $(7.29)$ & $(8.87)$ \\
Non-Hispanic Asian & $154,607(6.22)$ & $(9.30)$ & $(8.45)$ \\
Non-Hispanic American Indian & $24,992(0.84)$ & & $(7.18)$ \\
Age (years) & & $(9.08)$ & $(8.50)$ \\
12-19 & $237,060(9.54)$ & $(7.62)$ & $(8.39)$ \\
20-34 & $1,896,901(76.31)$ & $(8.99)$ & $(8.06)$ \\
35 or older & $351,782(14.15)$ & & $(7.78)$ \\
Education & & $(8.94)$ & $(5.99)$ \\
Less than high school & $506,474(20.38)$ & $(8.62)$ & $(8.58)$ \\
High school & $618,388(24.88)$ & $(8.26)$ & $(6.76)$ \\
Some college & $691,508(27.82)$ & $(6.28)$ & $(9.22)$ \\
$\quad$ Graduate school & $669,373(26.93)$ & $1,484,126(59.71)$ & \\
Marital Status & & & \\
Unmarried & $1,001,617(40.29)$ & & \\
Married & $1,40)$ & \\
\hline
\end{tabular}


Table 2 Percentage of all preterm births (20-<37 weeks gestation) and third trimester preterm births (28- <37 weeks gestation) by maternal smoking status, singleton births United States, 2010

\begin{tabular}{llll}
\hline Maternal Smoking Status & $\mathrm{N}(\%)$ & Preterm (\%) $20-<37$ weeks & Preterm (\%) 28-<37 weeks \\
\hline No trimester smokers & $2,253,887(90.67)$ & $(7.68)$ & $(7.23)$ \\
1st trimester only, low & $28,560(1.15)$ & $(8.90)$ & $(8.14)$ \\
1st trimester only, high & $4909(0.20)$ & $(8.68)$ & $(7.87)$ \\
1st \& 2nd trimesters, low & $11,619(0.47)$ & $(12.99)$ & $(10.58)$ \\
1st \& 2nd trimesters, high & $2835(0.11)$ & $(15.38)$ & $(12.57)$ \\
2nd \& 3rd trimesters, low & $5759(0.23)$ & $(8.73)$ & $(8.34)$ \\
2nd\& 3rd trimesters, high & $584(0.02)$ & $(9.42)$ & $(8.79)$ \\
All 3 trimesters, low & $130,060(5.23)$ & $(10.56)$ & $(10.09)$ \\
All 3 trimesters, high & $47,530(1.91)$ & $(11.35)$ & $(10.99)$ \\
\hline
\end{tabular}

Low intensity: 1-19 cigarettes/day; high intensity: $\geq 20$ cigarettes/day

that was most strongly linked to the risk of preterm birth. Our focus was on comparing prenatal exposure by trimester from the beginning of pregnancy and we assumed that women lower their smoking intensity and quit thereafter, thus low intensity smoking in the first trimester only was the reference category. [41] The main comparison involved women who smoked in the first and in the second trimester versus in the first trimester (referent), and those who smoked in the first, the second, and third trimester versus in the first trimester (referent). In order to determine which trimester smoking exposure was associated with the highest risk of preterm birth, we also examined inconsistent smokers. Significance level was set at $p=0.05$.

Additionally, we conducted a sensitivity analysis for potential exposure misclassification error based on maternal smoking self-reports by analyzing only those mothers who delivered in the third trimester, i.e., the second gestational age subgroup [44, 45] and separately tested for effect modification by maternal race/ethnicity on the association between high intensity smoking status in the first and the second trimester and the risk of preterm birth. [43, 47] The study analysis included the entire population, so weights were not utilized. SAS version 9.4 (SAS Institute Inc., Cary, NC) was used in all statistical computations.

This was a secondary analysis of deidentified and publicly available data and our study received Institutional Review Board (IRB) exemption from the University of Maryland. The authors have no financial or other conflict of interest.

\section{Results}

Nearly $7.95 \%$ of mothers had a preterm birth $(20-<37$ weeks gestation) by the most inclusive definition and $7.49 \%$ mothers delivered preterm in the third trimester (28 - < 37 weeks gestation) (Table 1; left- and right-hand panels, respectively). Over half (53.12\%) of mothers were
non-Hispanic White who had a preterm birth rate of 7.27 and $11.92 \%$ were non-Hispanic Black mothers with a preterm birth rate of $11.48 \%$.

More than $90 \%$ of women abstained from smoking during pregnancy (Table 2). Among women who smoked consistently during all three trimesters (7.14\%), 5.23\% smoked less than a pack/day and $1.91 \%$ smoked a pack/ day or more. Women who reported smoking less than a pack/day (low intensity smokers) in the first trimester only $(1.15 \%)$ were the reference category. In the first gestational age subgroup analysis (20 weeks gestation to term) $7.68 \%$ of women who abstained from smoking during pregnancy had a preterm birth (Table 2; left hand panel). In comparison, among women who smoked during all three trimesters, $10.56 \%$ of low intensity smokers (less than a pack/ day) and $11.35 \%$ of high intensity smokers (more than a pack/day) delivered preterm (Table 2; left hand panel). In the second gestational age subgroup (28 weeks gestation to term) the results were similar, but preterm birth rates were lower (Table 2, right hand panel).

Two logistic regression models display results of crude and adjusted odds ratios (Table 3). Mothers who abstained from smoking had about 10\% lower adjusted odds ratios of preterm birth in the first gestational age subgroup (aOR 0.90, 95\% CI: 0.86, 0.94; Table 3, upper panel) and $7 \%$ in the second gestational age subgroup analysis (aOR 0.93, 95\% CI: 0.89, 0.97; Table 3, lower panel), compared to the first trimester low intensity smokers (referent). Comparison of timing of prenatal exposure across trimesters indicates that not smoking in the first trimester but smoking in the second and third trimesters does not increase the risk of preterm birth, compared to smoking at low intensity in the first trimester only. Women who smoked more than a pack/day only in the first trimester did not have significantly higher odds of preterm birth, compared to women who smoked less than a pack a day (referent). In contrast, women who smoked less than a pack a day in the first 
Table 3 The odds of all preterm births (20- $<37$ weeks gestation) and third trimester preterm births (28- $<37$ weeks gestation) across maternal smoking status categories

\begin{tabular}{|c|c|c|c|c|}
\hline \multicolumn{5}{|c|}{ Preterm $20-<37$ weeks } \\
\hline Smoking Status & Crude OR & $95 \% \mathrm{Cl}$ & Adjusted $\mathrm{OR}^{\mathrm{a}}$ & $95 \% \mathrm{Cl}$ \\
\hline $\begin{array}{l}\text { No trimester } \\
\text { smokers }\end{array}$ & 0.85 & $0.82,0.89^{*}$ & 0.90 & $0.86,0.94^{*}$ \\
\hline $\begin{array}{l}\text { 1st trimester } \\
\text { only, low (ref.) }\end{array}$ & 1 & 1 & 1 & 1 \\
\hline $\begin{array}{l}\text { 1st trimester } \\
\text { only, high }\end{array}$ & 0.97 & $0.87,1.08$ & 0.98 & $0.88,1.09$ \\
\hline $\begin{array}{l}\text { 1st \& 2nd } \\
\text { trimesters, low }\end{array}$ & 1.53 & $1.43,1.64^{*}$ & 1.51 & $1.41,1.61^{*}$ \\
\hline $\begin{array}{l}\text { 1st \& 2nd } \\
\text { trimesters, high }\end{array}$ & 1.86 & $1.67,2.07^{*}$ & 1.85 & $1.66,2.06^{*}$ \\
\hline $\begin{array}{l}\text { 2nd \& 3rd } \\
\text { trimesters, low }\end{array}$ & 0.98 & $0.89,1.08$ & 0.95 & $0.86,1.05$ \\
\hline $\begin{array}{l}\text { 2nd \& 3rd } \\
\text { trimesters, high }\end{array}$ & 1.06 & $0.80,1.41$ & 1.03 & $0.77,1.36$ \\
\hline $\begin{array}{l}\text { All } 3 \text { trimesters, } \\
\text { low }\end{array}$ & 1.21 & $1.16,1.26^{*}$ & 1.20 & $1.14,1.25^{*}$ \\
\hline $\begin{array}{l}\text { All } 3 \text { trimesters, } \\
\text { high }\end{array}$ & 1.31 & $1.25,1.38^{*}$ & 1.33 & $1.26,1.40^{*}$ \\
\hline \multicolumn{5}{|c|}{ Preterm $28-<37$ weeks } \\
\hline Smoking Status & Crude OR & $95 \% \mathrm{Cl}$ & Adjusted $\mathrm{OR}^{\mathrm{a}}$ & $95 \% \mathrm{Cl}$ \\
\hline $\begin{array}{l}\text { No trimester } \\
\text { smokers }\end{array}$ & 0.88 & $0.84,0.92^{*}$ & 0.93 & $0.89,0.97^{*}$ \\
\hline $\begin{array}{l}\text { 1st trimester } \\
\text { only, low (ref.) }\end{array}$ & 1 & 1 & 1 & 1 \\
\hline $\begin{array}{l}\text { 1st trimester } \\
\text { only, high }\end{array}$ & 0.96 & $0.86,1.08$ & 0.97 & $0.86,1.08$ \\
\hline $\begin{array}{l}\text { 1st \& 2nd } \\
\text { trimesters, low }\end{array}$ & 1.34 & $1.24,1.44^{*}$ & 1.32 & $1.22,1.42^{*}$ \\
\hline $\begin{array}{l}\text { 1st \& 2nd } \\
\text { trimesters, high }\end{array}$ & 1.62 & $1.44,1.83^{*}$ & 1.61 & $1.43,1.82^{*}$ \\
\hline $\begin{array}{l}\text { 2nd \& 3rd } \\
\text { trimesters, low }\end{array}$ & 1.03 & $0.93,1.14$ & 1.00 & $0.90,1.11$ \\
\hline $\begin{array}{l}\text { 2nd \& 3rd } \\
\text { trimesters, high }\end{array}$ & 1.09 & $0.81,1.46$ & 1.05 & $0.79,1.40$ \\
\hline $\begin{array}{l}\text { All } 3 \text { trimesters, } \\
\text { low }\end{array}$ & 1.27 & $1.21,1.33^{*}$ & 1.25 & $1.20,1.31^{*}$ \\
\hline $\begin{array}{l}\text { All } 3 \text { trimesters, } \\
\text { high }\end{array}$ & 1.39 & $1.32,1.47^{*}$ & 1.40 & $1.33,1.48^{*}$ \\
\hline
\end{tabular}

${ }^{a}$ Analyses were adjusted for: maternal race/ethnicity, age, education, and marital status; low intensity: 1-19 cigarettes/day; high intensity: $\geq 20$ cigarettes/day; ${ }^{*} p<0.05$; Cl-confidence interval

and second trimesters had $51 \%$ higher odds of preterm birth (aOR 1.51, 95\% CI: 1.41, 1.61) than those who smoked less than a pack/day in the first trimester only (referent) (Table 3). Finally, women who smoked more than a pack a day in the first and second trimesters had $85 \%$ higher odds of preterm birth (aOR 1.85, 95\% CI: $1.66,2.06)$, compared to women who smoked less than a pack/day in the first trimester only (referent). This suggests that the late part of the first trimester is a potential vulnerability period during which smoking exerts its greatest effect on the risk of preterm birth.

Interestingly, smoking in all three trimesters at low intensity showed a somewhat reduced association (regression attenuation) with preterm birth in the first (aOR 1.20, 95\% CI: 1.14, 1.25) gestational age group, (Table 3; upper panel) relative to first trimester low intensity smoking (referent). We attributed these findings to an exposure misclassification error from suboptimal maternal self-reports. $[44,45]$ Mothers who delivered in the second trimester could not have smoked in the third trimester [38] and were excluded $(n=12,405 ; 0.46 \%)$ from the second gestational subgroup (i.e. third trimester births). Restricting the sample to the second gestational age subgroup (aOR 1.25, 95\% CI: 1.20, 1.31) (Table 3; lower panel) raises the association somewhat. Restricting the sample and changing the reference group to low intensity smoking in the first and second trimesters (Table 4, lower panel) allowed statistical comparison of the risk among three-trimester smokers to that of first and second trimester smokers. The crude and adjusted odds ratios of preterm birth no longer differed significantly for low or high intensity smokers in all three trimesters, compared to the two-trimester smokers (referent category) (Table 4, lower panel). The statistically increased risk of preterm birth conferred by consistent prenatal cigarette smoke exposure in the first and later trimesters compared to those who smoked in the first trimester only remained in this sensitivity analysis. [46] Testing for effect modification in the regression model by maternal race/ethnicity between high intensity smoking status in the first and second trimesters and the risk of preterm birth showed no significant interaction, which was consistent with a prior study. [47]

\section{Discussion}

Many women quit smoking during pregnancy to reduce risk of harm to the developing fetus but the rate of successful quit attempts is low. [36] Although understanding the implications of varied patterns of maternal smoking from the onset of pregnancy until the time of delivery would be informative to women and health professionals, research to date has been limited. [30, 48] A recent meta-analysis revealed that almost half of studies use a binary measure of maternal smoking, usually collected after delivery, and poorly define intensity levels. [49] The present study assessed how the odds of preterm birth vary according to measures of timing (per trimester), intensity (the number of cigarettes smoked per day) and duration (consistency) of smoking in pregnancy, using first trimester quitting as a reference category. Women who did not smoke during the first trimester had a risk of preterm birth similar to those who quit during that trimester. Women who smoked more than a 
Table 4 The odds of all preterm births (20- $<37$ weeks gestation) and third trimester preterm births $(28-<37$ weeks) across maternal smoking status categories (alternate reference)

\begin{tabular}{|c|c|c|c|c|}
\hline \multicolumn{5}{|l|}{ Preterm $20-<37$ weeks } \\
\hline Smoking Status & Crude OR & $95 \% \mathrm{Cl}$ & Adjusted $O R^{a}$ & $95 \% \mathrm{Cl}$ \\
\hline $\begin{array}{l}\text { No trimester } \\
\text { smokers }\end{array}$ & 0.56 & $0.53,0.59^{*}$ & 0.60 & $0.57,0.63^{*}$ \\
\hline $\begin{array}{l}\text { 1st trimester only, } \\
\text { low }\end{array}$ & 0.65 & $0.61,0.70^{*}$ & 0.66 & $0.62,0.71^{*}$ \\
\hline $\begin{array}{l}\text { 1st trimester only, } \\
\text { high }\end{array}$ & 0.64 & $0.57,0.71^{*}$ & 0.65 & $0.58,0.73^{*}$ \\
\hline $\begin{array}{l}\text { 1st \& 2nd } \\
\text { trimesters, low (ref.) }\end{array}$ & 1 & 1 & 1 & 1 \\
\hline $\begin{array}{l}\text { 1st \& 2nd } \\
\text { trimesters,high }\end{array}$ & 1.22 & $1.09,1.37^{*}$ & 1.23 & $1.09,1.38^{*}$ \\
\hline $\begin{array}{l}\text { 2nd \& 3rd } \\
\text { trimesters, low }\end{array}$ & 0.64 & $0.58,0.71^{*}$ & 0.63 & $0.57,0.70^{*}$ \\
\hline $\begin{array}{l}\text { 2nd \& 3rd } \\
\text { trimesters, high }\end{array}$ & 0.70 & $0.53,0.92^{*}$ & 0.68 & $0.51,0.90^{*}$ \\
\hline $\begin{array}{l}\text { All } 3 \text { trimesters, } \\
\text { low }\end{array}$ & 0.79 & $0.75,0.84^{*}$ & 0.79 & $0.75,0.84^{*}$ \\
\hline $\begin{array}{l}\text { All } 3 \text { trimesters, } \\
\text { high }\end{array}$ & 0.86 & $0.81,0.91^{*}$ & 0.88 & $0.83,0.94^{*}$ \\
\hline \multicolumn{5}{|l|}{ Preterm $28-<37$ weeks } \\
\hline Smoking Status & Crude OR & $95 \% \mathrm{Cl}$ & Adjusted $\mathrm{OR}^{\mathrm{a}}$ & $95 \% \mathrm{Cl}$ \\
\hline $\begin{array}{l}\text { No trimester } \\
\text { smokers }\end{array}$ & 0.66 & $0.62,0.70^{*}$ & 0.70 & $0.66,0.75^{*}$ \\
\hline $\begin{array}{l}\text { 1st trimester } \\
\text { only, low }\end{array}$ & 0.75 & $0.70,0.81^{*}$ & 0.76 & $0.71,0.82^{*}$ \\
\hline $\begin{array}{l}\text { 1st trimester } \\
\text { only, high }\end{array}$ & 0.72 & $0.64,0.82^{*}$ & 0.73 & $0.65,0.83^{*}$ \\
\hline $\begin{array}{l}\text { 1st \& 2nd } \\
\text { trimesters, low (ref.) }\end{array}$ & 1 & 1 & 1 & 1 \\
\hline $\begin{array}{l}\text { 1st \& 2nd } \\
\text { trimesters, high }\end{array}$ & 1.22 & $1.07,1.38^{*}$ & 1.22 & $1.08,1.39^{*}$ \\
\hline $\begin{array}{l}\text { 2nd \& 3rd } \\
\text { trimesters, } \\
\text { low }\end{array}$ & 0.77 & $0.69,0.86^{*}$ & 0.76 & $0.68,0.85^{*}$ \\
\hline $\begin{array}{l}\text { 2nd \& 3rd } \\
\text { trimesters, high }\end{array}$ & 0.82 & $0.61,1.09$ & 0.80 & $0.59,1.07$ \\
\hline $\begin{array}{l}\text { All } 3 \text { trimesters, } \\
\text { low }\end{array}$ & 0.95 & $0.89,1.01$ & 0.95 & $0.89,1.01$ \\
\hline $\begin{array}{l}\text { All } 3 \text { trimesters, } \\
\text { high }\end{array}$ & 1.04 & $0.98,1.12$ & 1.07 & $0.99,1.14$ \\
\hline
\end{tabular}

${ }^{a}$ Analyses were adjusted for: maternal race/ethnicity, age, education, and marital status; low intensity: 1-19 cigarettes/day; high intensity: $\geq 20$ cigarettes $/$ day; ${ }^{*} p<0.05$; Cl-confidence interval

pack/day in the first trimester only did not have significantly higher odds of preterm birth compared to women who smoked less than a pack a day in the first trimester only (referent). This suggests that there is a window of time wherein quitting keeps the risk of preterm birth to a level comparable to nonsmokers, and intensity does not affect this risk. In contrast, women who smoked less or more than a pack a day in the first and second trimesters had a significantly higher odds of preterm birth compared to the referent category. Additionally, those who did not report smoking in the first trimester but smoked later did not have higher risk of preterm birth. The period late in the first and early in the second trimester is a potential biologically plausible vulnerability window for the risk of preterm birth that has been proposed in prior research $[19,21]$ and this research suggests that it is most pronounced late in the first trimester.

There may be substantial placental risks at about weeks 12 and 13 that have not yet been fully identified. It is already known that during the first trimester nicotine can interfere with hypoxic embryogenesis, placentation and organogenesis by generating excess reactive oxygen species resulting in direct oxidative damage to the nuclear deoxyribonucleic acid (DNA) [50] Around the end of the first trimester and start of the second trimester, toxic nicotine effects can cause abnormal remodeling of the spiral arteries supplying the placenta and reducing nutrition and oxygen transfer required for proper fetal growth. [50] Dysregulated functional and programming capacity of the placental-fetal unit is likely to influence preterm birth. [51-54]

Although, we have come close, we cannot establish this gestational window precisely because of the lack of detailed information in the dataset on when first trimester smokers quit and when second trimester initiators began smoking. Interestingly, smoking in all three trimesters was associated with a lower risk of preterm birth than smoking in the first two trimesters (referent), and the difference in risks was statistically significant. Because smoking is less likely to be overestimated in the first and second trimesters, we attributed these findings to a potential exposure misclassification error from suboptimal maternal self-reports of trimester of smoking on the birth certificate. [38, 48] In sensitivity analysis, under correct assumptions for binary exposure misclassification, [44-46] these findings were adjusted, raising three-trimester smoking risk to the level of two-trimester risk. Testing for effect modification by maternal race/ethnicity found no significant interaction which was consistent with prior research by Moore et al. [47]

To our knowledge, this is the first population-based study to examine how prenatal exposure measured by combined timing, duration and intensity of smoking is associated with an increased likelihood of delivering preterm. Ideally, the present study should be extended to reoccurring preterm birth and other adverse pregnancy outcomes. [55] Given the complexity of preterm birth syndrome, $[56,57]$ this epidemiological evidence integrated with biological and clinical knowledge will improve birth outcomes in women considered at a high risk of preterm delivery. 


\section{Strengths and limitations}

The main strength of our study was the availability of a large national dataset of over 2 million live U.S. births that contains information on maternal smoking behavior during each trimester of pregnancy. Revised birth certificates with enhanced health data on mothers and infants can expand opportunities in perinatal research. There are also a few limitations. One limitation is that the study population is not representative of the entire U.S. population, because in 2010 only $76 \%$ of all US states used the revised birth certificate. This still represents an advance over previous research that used data from one individual state $[21,47]$ or from a smaller set of states. [19] Similar to prior research, we excluded multiple births and data with missing covariates. There is a lack of information in the birth certificate on other risk factors that could confound the association between maternal smoking and preterm birth, such as exposure to passive smoking. Potential for exposure misclassification exists from maternal self-reports on smoking that may be underreported or prone to recall bias. [36, 41, 45] As we addressed in the sensitivity analysis, women who deliver preterm in the second trimester may inadvertently misreport smoking in the third trimester, becoming self-designated "third trimester smokers".

\section{Conclusions}

Women appear motivated to quit smoking during pregnancy; however, behavioral change is difficult to initiate and maintain. Knowing a period of vulnerability in which smoking exposure could harm a developing fetus and raise the risk of preterm birth would help health professionals to inform reproductive age and pregnant women. Early smoking cessation interventions may have a greater effect on the reduction of preterm birth, not just because the majority of women who smoke in the first trimester continue to smoke throughout pregnancy, but because the vulnerability period for smoking exposure appears late in the first trimester. Ultimately, findings from this study may guide future research in understanding the etiology and mechanisms of other adverse birth outcomes (e.g. low birthweight, placenta praevia) and in developing potential screening or risk prediction biomarkers and therapeutic targets.

\section{Abbreviations \\ aOR: Adjusted odds ratio; Cl: Confidence interval; DNA: Deoxyribonucleic acid; IRB: Institutional Review Board; LMP: Last menstrual period; NCHS: National Center for Health Statistics; OE: Obstetric estimate; PRAMS: Pregnancy Risk Assessment Monitoring System; US: Ultrasound}

Acknowledgements

Not applicable.

\section{Funding}

Support for this research was provided by the Eunice Kennedy Shriver National Institute of Child Health and Human Development (Grant R01-
HD053654, S. Hofferth, PI, and R24-HD041041 to the Maryland Population Research Center). Partial funding for open access provided by the UMD Libraries' Open Access Publishing Fund.

\section{Availability of data and materials}

The dataset analyzed during the current study is publicly available from the National Center for Health Statistics (NCHS) Vital Statistics Natality Birth Data and can be accessed through the National Bureau of Economic Research website: http://www.nber.org/data/vital-statistics-natality-data.html.

\section{Authors' contributions}

AJK contributed to the study concept, data analysis and drafting of the paper. AJK and SLH were equally responsible for the study design, acquisition of data, revising, and approving the final version of the manuscript.

\section{Ethics approval and consent to participate}

Not applicable.

\section{Consent for publication}

Not applicable.

\section{Competing interests}

The authors declare that they have no competing interests.

\section{Publisher's Note}

Springer Nature remains neutral with regard to jurisdictional claims in published maps and institutional affiliations.

Received: 13 January 2019 Accepted: 1 April 2019

Published online: 16 April 2019

References

1. Romero R, Dey SK, Fisher SJ. Preterm labor: one syndrome, many causes. Science 2014; 345(6198):760-765. PMID: 25124429 Doi https://doi.org/10. 1126/science.

2. US Department of Health and Human Services. (USDHHS). Office of Disease Prevention and Health Promotion. Healthy People 2020: Maternal, infant, and child health. Washington DC; 2018.

3. Martin JA, Hamilton BE, Osterman MJK, Driscoll AK, Births DP. Final data for 2017. Division of vital statistics. National Vital Statistics Report. 2018:67 (8).

4. Ananth CV, Vintzileos AM. Epidemiology of preterm birth and its clinical subtypes. J Matern Fetal Neonatal Med. 2006;19:773-82.

5. Mathews TJ, MacDorman MF. Infant Mortality Statistics from the 2010 Period Linked Birth/Infant Death Data Set. National Vital Statistics Report. 2013 Dec;62(8).

6. Institute of Medicine (IOM). Preterm Birth: Causes, Consequences, and Prevention. Behrman R \& Butler AS (eds). Washington, DC: National Academies Press; 2007.

7. Curtin SC, Mathews TJ. National Vital Statistics Reports Smoking Prevalence and cessation before and during pregnancy: data from the birth certificate, 2014. Natl Vital Stat Reports. 2016;65(1):1-14. https://doi.org/10.1016/j.clay. 2003.10.002

8. Talhout R, Schulz T, Florek E, et al. Hazardous compounds in tobacco smoke. Int J Environ Res Public Health. 2011;8(2):613-28.

9. Blatt K, Moore E, Chen A, Van Hook J, DeFranco EA. Association of reported trimester-specific smoking cessation with fetal growth restriction. Obstet Gynecol. 2015;125(6):1452-9.

10. Jaddoe WW, Troe EJ, Hofman A, et al. Active and passive maternal smoking during pregnancy and the risks of low birthweight and preterm birth: the generation R study. Paediatr Perinat Epidemiol. 2008;22(2):162-71.

11. Aagaard-Tillery KM, Porter TF, Lane RH, Varner MW, Lacoursiere DY. In utero tobacco exposure is associated with modified effects of maternal factors on fetal growth. Am J Obstet Gynecol. 2008;198(66):e1-66.e6.

12. Pineles BL, Park E, Samet JM. Systematic review and meta-analysis of miscarriage and maternal exposure to tobacco smoke during pregnancy. Am J Epidemiol. 2014;179(7):807-23.

13. Aliyu MH, Wilson RE, Alio AP, Kristensen S, Marty PJ, Whiteman VE, Salihu HM. Association between tobacco use in pregnancy and placentaassociated syndromes: a population-based study. Arch Gynecol Obstet 2011 283(4):729-734. PubMed: 20354707 
14. Petrou $\mathrm{S}$. The economic consequences of preterm birth during the first 10 years of life. Br J Obstet Gynaecol. 2005;112(Suppl 1):S10-5.30.

15. Tong VT, Dietz PM, Morrow B, D'Angelo DV, Farr SL, Rockhill KM, England LJ. Trends in smoking before, during, and after pregnancypregnancy risk assessment monitoring system, United States, 40 sites, 2000-2010. MMWR Surveill Summ. 2013;62:1-19.

16. DiClemente CC, Dolan-Mullen P, Windsor RA. The process of smoking during pregnancy: implications for interventions. Tobacco Control. 2000; 9(Suppl III):iii16-iii219.

17. Kyrklund-Blomberg NB, Granath F, Cnattingius S. Maternal smoking and causes of very preterm birth. Acta Obstet Gynecol Scand. 2005;84:572-7.

18. McCowan LM, Dekker GA, Chan E, Stewart A, Chappell LC, et al. SCOPE consortium. Spontaneous preterm birth and small for gestational age infants in women who stop smoking early in pregnancy: prospective cohort study. British Med J. 2009;338:b1081.

19. Polakowski $L L$, Akinbami $L$, Mendola P. Prenatal smoking cessation and the risk of delivering preterm and small-for-gestational-age newborns. Obstet Gynecol. 2009;114(2):318-25.

20. Ko T-J, Tsai LY, Chu LC, et al. Parental smoking during pregnancy and its association with low birth weight, small for gestational age, and preterm birth offspring: a birth cohort study. Pediatrics and Neonatology. 2014;55: $20 \mathrm{e} 27$.

21. Moore E, Blatt K, Chen A, Van Hook J. DeFranco EA. Factors Associated with Smoking Cessation in Pregnancy Am J Perinatol. 2016;33(6):560-8.

22. National Center for Health Statistics. Vital statistics data online. Retrieved Jan 5, 2019 from: https://www.cdc.gov/nchs/data_access/vitalstatsonline.htm

23. National Center for Health Statistics. 2003 Revisions of the US Standard Certificates of Live Birth and Death and the Fetal Death Report. http://www. cdc.gov/nchs/data/dvs/birth11-03final-acc.pdf

24. Ventura SJ. The U.S. National Vital Statistics System: transitioning into the 21st century, 1990-2017. Vital Health Stat. 2018:62:1-84.

25. American Academy of Pediatrics (AAP), American College of Obstetricians and Gynecologists (ACOG). Guidelines for perinatal care. 7th ed. 2012. http://www.circulomedicodezarate.org/e-books/Guidelines_for_Perinatal_ Care.pdf

26. Martin JA, Osterman MJK, Kirmeyer SE, Gregory ECW. Measuring gestational age in vital statistics data: Transitioning to the obstetric estimate. National Center for Health Statistics. Hyattsville, MD. National Vital Statistics Reports 2015; 64(5).

27. Dietz PM, Bombard JM, Hutchings YL, et al. Validation of obstetric estimate of gestational age on US birth certificates. Am J Obstet Gynecol. 2014; 210(4):335.e1-5. https://doi.org/10.1016/j.ajog.2013.10.875.

28. Chang HH, Warren JL, Darrow LA, Reich BJ, Waller LA. Assessment of critical exposure and outcome windows in time-to-event analysis with application to air pollution and preterm birth study. Biostatistics. 2015 Jul;16(3):509-21.

29. Lemasters GK, Perreault SD, Hales BF, Hatch M, Hirshfield AN, Hughes CL, et al. Workshop to identify critical windows of exposure for children's health: reproductive health in children and adolescents work group summary. Environ Health Perspect. 2000;108:505-9.

30. Eiden RD, Homish GG, Colder CR, Schuetze P, Gray TR, Huestis MA. Changes in smoking patterns during pregnancy. Subst Use Misuse. 2013;48(7):513-22.

31. Pickett $K$, Wakschlag $L$, Leventhal B. Maternal smoking during pregnancy: not a stable phenomenon. Paediatr Perinat Epidemiol 2001;15(4):A27-A27. Doi:https://doi.org/10.1111/j.1365-3016.2001.381-84.x.

32. Pickett KE, Rathouz PJ, Kasza K, Wakschlag LS, Wright R. Self-reported smoking, cotinine levels, and patterns of smoking in pregnancy. Pediatric and Perinatal Epidemiology. 2005;19:368-76.

33. Caraballo R, Giovino G, Pechacek T, Mowery P. Factors associated with discrepancies between self-reports on cigarette smoking and measured serum cotinine levels among persons aged 17 years and older. Am J Epidemiol. 2001;153:807-14.

34. Klebanoff MA, Levine RJ, Morris CD, Hauth JC, Sibai BM, Curet LB, Catalano P, Wilkins DG. Accuracy of self-reported cigarette smoking among pregnant women in the 1990s. Paediatr Perinat Epidemiol. 2001;15:140-3

35. Searles Nielsen S, Dills RL, Glass M, Mueller BA. Accuracy of prenatal smoking data from Washington state birth certificates. In a populationbased sample with cotinine measurements. Ann Epidemiol. 2014;24:236-9.
36. Tong VT, Althabe F, Alemán A, Johnson CC, Dietz PM, Berrueta M, Morello P, Colomar M, Buekens P, Sosnoff CS. Prenatal tobacco cessation intervention collaborative. Accuracy of self-reported smoking cessation during pregnancy. Acta Obstet Gynecol Scand. 2015;94(1):106-11.

37. Dietz PM, Adams MM, Kendrick JS, Mathis MP. Completeness of ascertainment of prenatal smoking using birth certificates and confidential questionnaires: variations by maternal attributes and infant birth weight. PRAMS working group. Pregnancy risk assessment monitoring system. Am J Epidemiol. 1998;148(11):1048-54.

38. Pickett KE, Kasza K, Biesecker G, Wright RJ. Wakschlag L.S. women who remember, women who do not: a methodological study of maternal recall of smoking in pregnancy. Nicotine Tob Res. 2009; 11(10):1166-74

39. Ashford K, Wiggins A, Rayens E, Assef S, Fallin A, Rayens MK. Perinatal biochemical confirmation of smoking status by trimester. Nicotine Tob Res. 2017 May 1;19(5):631-5. https://doi.org/10.1093/ntr/ntw332.

40. Benowitz NL, Jacob P III, Ahijevych K, et al. Biochemical verification of tobacco use and cessation. Nicotine Tob Res. 2002;4:149-59.

41. England $\sqcup$, Grauman A, Qian C, Wilkins DG, Schisterman EF, Yu KF, Levine RJ. Misclassification of maternal smoking status and its effects on an epidemiologic study of pregnancy outcomes. Nicotine Tob Res. 2007;9:1005-13.

42. George L, Granath F, Johansson ALV, Cnattingius S. Self-reported nicotine exposure and plasma levels of cotinine in early and late pregnancy. Acta Obstet Gynecol Scand. 2006;85(11):1331-7. https://doi.org/10.1080/ 00016340600935433.

43. Shaw RJ, Pickett KE, Wilkinson RG. Ethnic density effects on birth outcomes and maternal smoking during pregnancy in the US linked birth and infant death data set. J Public Health. 2010;100:707-13. https://doi.org/10.2105/ AJPH.2009.167114.

44. Greenland S, Lash TL. Bias Analysis. In: Rothman KJ, Greenland S, Lash TL, editors. Modern Epidemiology. Philadelphia, PA: Lippincott Williams \& Wilkins; 2008. p. 345-80.

45. Radin RG, Rothman KJ, Hatch EE, et al. Maternal recall error in retrospectively-reported time-to pregnancy: an assessment and bias analysis. Paediatr Perinat Epidemiol. 2015;29(6):576-88.

46. Johnson CY, Flanders WD, Strickland MJ, Honein MA, Howards PP. Potential sensitivity of bias analysis results to incorrect assumptions of nondifferential or differential binary exposures misclassification. Epidemiology. 2014 Nov; 25(6):902-9

47. Moore E, Blatt K, Chen A, Van Hook J, De Franco EA. Relationship of trimester-specific Smoking patterns and risk of preterm birth. Am J Obstet Gynecol. 2016 Jul;215(1):109.e1-6. https://doi.org/10.1016/j.ajog. 2016.01.167.

48. Pickett KE, Wakschlag LS, Dai L, Leventhal BL. Fluctuations of maternal smoking during pregnancy. Obstet Gynecol. 2003;101:140-7.

49. Marufu TC, Ahankari A, Coleman T, Lewis S. Maternal smoking and the risk of stillbirth: systematic review and meta-analysis. BMC Public Health. 2015; 15:239.

50. Burton GJ, Watson AL, Hempstock J, Skepper JN, Jauniaux E. Uterine glands provide histiotrophic nutrition for the human fetus during the first trimester of pregnancy. J Clin Endocrinol Metab. 2002 Jun; 87(6):2954-2959. PMID 12050279 DOl: https://doi.org/10.1210/jcem.87.6.8563.

51. Partap U, Sovio U, Smith GC. Fetal growth and the risk of spontaneous preterm birth in a prospective cohort study of nulliparous women. Am J Epidemiol. 2016;184(2):110e119. https://doi.org/10.1093/aje/kwv345.

52. Smith GC, Stenhouse EJ, Crossley JA et al. Early pregnancy levels of pregnancy-associated plasma protein $A$ and the risk of intrauterine growth restriction, premature birth, preeclampsia, and stillbirth. J Clin Endocrinol Metab . 2002;874:1762-1767. PMID 11932314 DOI: https://doi.org/10.1210/jcem.87.4.8430

53. Salafia CM, Vogel CA, Bantham KF, Vintzileos AM, Pezzullo J, Silberman L. Preterm delivery: correlations of fetal growth and placental pathology. Am J Perinatol. 1992;9:190-3. https://doi.org/10.1055/s-2007-999318.

54. Romero R, Mazaki-Tovi S, Vaisbuch E, Kusanovic JP, Chaiworapongsa T, Gomez R, Nien JK, Yoon BH, Mazor M, Luo J, Banks D, Ryals J, Beecher C. Metabolomics in premature labor: a novel approach to identify patients at risk for preterm delivery. J Matern Fetal Neonatal Med. 2010;23:1344-59. https://doi.org/10.3109/14767058.2010.482618.

55. Ananth CV, Demissie K, Smulian JC, Vintzileos AM. Relationship among placenta previa, fetal growth restriction, and preterm delivery: a population- 
based study. Obstet Gynecol. 2001 Aug;98(2):299-306. https://doi.org/10. 1016/S0029-7844(01)01413-2.

56. Menon R, Bonney EA, Condon J, Mesiano S, Taylor RN. Novel concepts on pregnancy clocks and alarms: redundancy and synergy in human parturition. Hum Reprod Update. 2016;22(5):535-60.

57. Hertz-Picciotto I, Pastore LM, Beaumont JJ. Timing and patterns of

exposures during pregnancy and their implications for study methods. Am J Epidemiol. 1996;143(6):199.

Ready to submit your research? Choose BMC and benefit from:

- fast, convenient online submission

- thorough peer review by experienced researchers in your field

- rapid publication on acceptance

- support for research data, including large and complex data types

- gold Open Access which fosters wider collaboration and increased citations

- maximum visibility for your research: over $100 \mathrm{M}$ website views per year

At BMC, research is always in progress.

Learn more biomedcentral.com/submissions 